\title{
Chemical Vapor Deposition Coating for Micromachines
}

S. S. MANI*, J. G. FLEMING, J. J. SNIEGOWSKI, M. P. DE BOER, L. W. IRWIN, J. A.
WALRAVEN, D. M. TANNER, and M. T. DUGGER
*MS 1084, PO Box 5800, Sandia National Laboratories, Albuquerque, NM 87185-1084,
ssmani @sandia.gov
ABSTRACT

Two major problems associated with Si-based MEMS devices are stiction and wear. Surface modifications are needed to reduce both adhesion and friction in micromechanical structures to solve these problems. In this paper, we will present a process used to selectively coat MEMS devices with tungsten using a CVD (Chemical Vapor Deposition) process. The selective $\mathrm{W}$ deposition process results in a very conformal coating and can potentially solve both stiction and wear problems confronting MEMS processing. The selective deposition of tungsten is accomplished through silicon reduction of $\mathrm{WF}_{6}$, which results in a self-limiting reaction. The selective deposition of $\mathrm{W}$ only on polysilicon surfaces prevents electrical shorts. Further, the self-limiting nature of this selective $\mathrm{W}$ deposition process ensures the consistency necessary for process control. Selective tungsten is deposited after the removal of the sacrificial oxides to minimize process integration problems. This tungsten coating adheres well and is hard and conducting, requirements for device performance. Furthermore, since the deposited tungsten infiltrates under adhered silicon parts and the volume of W deposited is less than the amount of $\mathrm{Si}$ consumed, it appears to be possible to release stuck parts that are contacted over small areas such as dimples. Results from tungsten deposition on MEMS structures with dimples will be presented. The effect of wet and vapor phase cleans prior to the deposition will be discussed along with other process details. The $\mathrm{W}$ coating improved wear by orders of magnitude compared to uncoated parts. Tungsten CVD is used in the integrated-circuit industry, which makes this approach manufacturable.

\section{INTRODUCTION}

MEMS devices are currently fabricated from polycrystalline silicon which is used by the silicon IC (integrated circuit) industry as a gate electrode and local interconnect [1]. The MEMS community has adopted a slightly modified IC (integrated circuit) polysilicon deposition process and makes polysilicon the cornerstone of nearly all surface micromachined devices. Parts fabricated from polysilicon, a material developed for its electronic and not mechanical properties have been demonstrated to be robust [2]. The primary devices to benefit from multilevel processing are micromechanical actuators. Unfortunately, micromechanical actuators have not seen the wide-spread industrial acceptance that micromechanical sensors have enjoyed. Figure 1 shows an example of a complex five level polysilicon MEMS part, fabricated at Sandia National Laboratories using surface micromachining, with numerous contacting, rubbing, moving, and impacting surfaces. Several stumbling blocks to the wide spread application of such complex systems are low force/torque levels, difficulty in coupling to engines, and susceptibility to surface effects such as stiction, friction, and wear. Some of these issues can be addressed adequately by design but the surface phenomena of stiction, friction and wear present the greatest impediment to common usage. As expected friction and wear greatly impact the performance of the microengine and associated structures. Several researchers have looked at methods of reducing both friction and wear such as liquid lubricants, SAMs (Self Assembled Monolayers) coatings, fluorocarbon coatings, and solid lubricants. 


\section{DISCLAIMER}

This report was prepared as an account of work sponsored by an agency of the United States Government. Neither the United States Government nor any agency thereof, nor any of their employees, make any warranty, express or implied, or assumes any legal liability or responsibility for the accuracy, completeness, or usefulness of any information, apparatus, product, or process disclosed, or represents that its use would not infringe privately owned rights. Reference herein to any specific commercial product, process, or service by trade name, trademark, manufacturer, or otherwise does not necessarily constitute or imply its endorsement, recommendation, or favoring by the United States Government or any agency thereof. The views and opinions of authors expressed herein do not necessarily state or reflect those of the United States Government or any agency thereof. 


\section{DISCLAIMER}

Portions of this document may be illegible in electronic image products. Images are produced from the best available original document. 


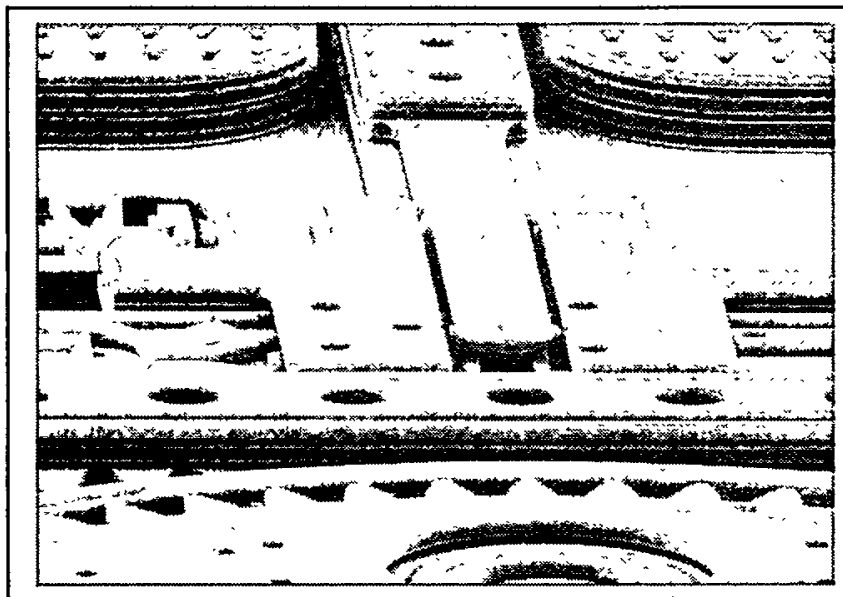

Figure 1. An example of a complex, five level MEMS structure fabricated using surface micromaching at Sandia National Laboratories. Stiction and wear are problems in processing such highly complex systems with numerous contacting, rubbing, moving and impacting surfaces.
In the case of liquid lubricants, the formation of menisci and their accompanying surface tension forces make localized liquid lubrication impractical. Liquid lubrication therefore requires total immersion of the devices. Operation of devices in a liquid typically tends to make the device behavior more repeatable and uniform. Unfortunately, the speed of operation in these fluids is greatly reduced relative to operation in air due to viscous drag. Also, other failure mechanisms such as slow drifting of contaminants in the fluid due to electrostatic attractive forces can be problems.

Earlier research [3-9] suggests that both friction and wear can be decreased with the application of SAMs. Whether the effects of SAMs are beneficial to friction and wear needs to be determined for the class of

devices with sliding friction (as opposed to rolling friction) such as the microengine. Henck [9] studied the wear behavior of the SAMs coatings and found an initial reduction in the coefficient of friction (cof), followed by slightly longer lifetime than untreated surfaces with time. The SAMs appeared to wear off and the device started to behave as an untreated surface. Such behavior is not desirable for long lifetime application of MEMS devices.

Studies [10] show conformal deposition of fluorocarbon (Teflon like) films onto released structures may also eliminate stiction and reduce wear. Results indicate a tough, very stable film, which conformally coats the released structures. The cof is less than 0.1 , comparable to bulk Teflon ${ }^{\mathrm{TM}}$; however, these films also demonstrate wear-off behavior and device lifetime has not been extended dramatically.

The use of solid lubricants with dissimilar hardness in bushing applications for rotating devices is common in the macro world. This concept has been extended the micro-world. Films such as diamond like carbon, silicon carbide, and silicon nitride for example have been proposed and used in microstructures. Constraints on the films include compatibility with the process and process tool set and whether it can be deposited on the proper surfaces. This area continues to show potential in dealing with friction and wear, and new films such as tungsten deposited using chemical vapor deposition techniques are continually being explored.

A fundamentally different approach to the wear problem is to substitute the polysilicon with intrinsically hard materials such as diamond or silicon carbide. However, this runs counter to the great enabling strength of surface micromachining, leveraging of IC processing technology and tool sets. An even bigger drawback to this approach involves process integration. Most devices with contacting layers consist of a minimum of three mechanical levels fabricated using a complicated combination of deposition, photolithographic, etch, and planarization processes. The introduction of completely new materials and processing technologies into these complex process flows would be very difficult. Most of the approaches suggested increase processing complexity and are not supported by standard IC equipment sets. Therefore, development of better surface passivation and tribological coatings using standard IC processing tool set is of great importance for the successful widespread introduction of microelectromechanical systems 
(MEMS) sensors and actuators. This is important since a key to the rapid growth of the MEMS technology has been the leveraging standard silicon processing technology.

In this paper we present a process used to selectively coat MEMS devices with tungsten using a CVD (Chemical Vapor Deposition) process. The deposition of a thin, self-limiting, low temperature, selective deposition of tungsten onto the structural polysilicon at the end of the fabrication process will be described. The selective tungsten is deposited after the removal of the sacrificial oxides to minimize process integration problems. Tungsten has a number of attractive properties as a wear resistant coating with excellent step coverage and self limiting reaction. The selective deposition of tungsten through the silicon reduction of $\mathrm{WF}_{6}$ was studied in detail in the late 1980's but never gained acceptance by the IC industry [11-16]. The process is accomplished through silicon reduction of $\mathrm{WF}_{6}$, which results in a self-limiting reaction $[15,16]$. The selflimiting nature of this selective $W$ deposition process ensures the consistency necessary for process control. The selective $\mathrm{W}$ deposition process results in a very conformal coating. Furthermore, since the deposited tungsten infiltrates under adhered silicon parts and the volume of W deposited is less than the amount of Si consumed, it appears to be possible to release stuck parts that are contacted over small areas such as dimples. Endurance of the W coating is important, especially in applications where wear due to repetitive contacts with the film may occur. Unlike the polymers, $\mathrm{W}$ is entirely compatible with the temperatures typically associated with packaging and is ultra high vacuum compatible. Tungsten CVD is used in the integratedcircuit industry, which makes this approach manufacturable.

\section{REACTION CHEMISTRY}

The silicon displacement reactions for selective $\mathrm{W}$ deposition are given below:

$$
2 W_{6}+3 S i \longrightarrow 2 W+3 S i F_{4} \uparrow
$$

and

$$
W F_{6}+3 \mathrm{Si} \longrightarrow W+3 \mathrm{SiF}_{2} \uparrow
$$

During the silicon displacement reaction, $W_{6}$ first dissociates on the Si surface forming $W_{\mathrm{x}}$ $(\mathrm{x}<6)$ adsorbed on the surface, and then further reduces to $\mathrm{W}$. At the same time, Si is converted to $\mathrm{SiF}_{\mathrm{x}}(\mathrm{x} \geq 1)$ and further changes to $\mathrm{SiF}_{4}$ or $\mathrm{SiF}_{2}$ based on the reaction temperature. Thus $\mathrm{Si}$ reduces the $W F_{6}$ molecules leading to the deposition of a $W$ film. Once a continuous film of $W$ is formed (after $\sim 200 \AA$ ) the $W_{6}$ is shielded from the $\mathrm{Si}$ and the reaction slows or stops, since the $\mathrm{WF}_{6}$ can no longer diffuse through the $\mathrm{W}$ (product) film to react with the underlying Si. This process is completely selective since the reaction proceeds only in the presence of $\mathrm{Si}$, hence the W deposition can not occur on silicon dioxide or silicon nitride [17].

\section{Self Limiting Nature of Reaction}

The self-limiting nature of the reaction was confirmed by measuring the thickness of $W$ films deposited for different lengths of times. Tungsten was deposited at $450^{\circ} \mathrm{C}$ on 6 " Si wafers with $2000 \AA$ undoped polysilicon in Genus 8720 . The reaction times were 2, 4, 8, and 16 minutes. The thickness was measured using Rutherford Back Scattering (RBS). The integrated value (W atoms $/ \mathrm{cm}^{2}$ ) under the curve for the different wafers is given in Table I. The error in the data is \pm 1.0E15. Assuming a nominal density of $19.3 \mathrm{gm} / \mathrm{cc}$ for tungsten and a beam size of $2.5 \mathrm{~mm} \mathrm{x}$ $2.5 \mathrm{~mm}$, the thickness of the film for the different deposition times varies from $68 \AA$ to $93 \AA$ as shown in Table 1. The fact that the film thickness initially increases rapidly but then is less than $100 \AA$ over 16 minutes of deposition time indicates a self limiting reaction taking place. The 
gradual increase in thickness is possibly the result of the presence of small regions of surface contamination hindering the formation of a continuous film.

\section{Tungsten Deposition Process:}

The selective $W$ deposited on polysilicon surfaces is extremely conformal as shown in a SEM micrograph in Figure 2. Polysilicon has been etched using $\mathrm{HNO}_{3}$ : $\mathrm{HF}$ to delineate the extremely thin $\mathrm{W}$ coating around the polysilicon structure, which is a portion of a hub. The W on the top surface is continuous even after the aggressive etch, demonstrating the absence of pin holes which would have been

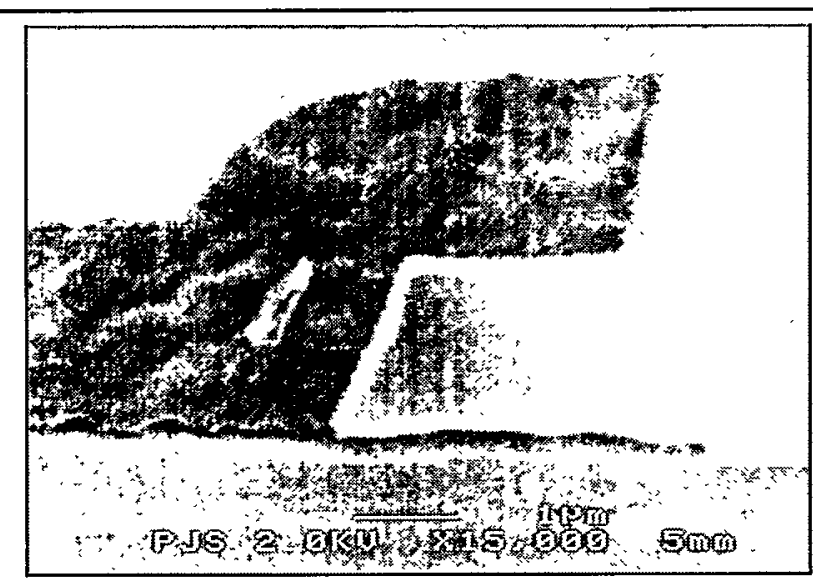

Figure 2. A scanning electron micrograph showing a thin $\sim 100 \AA$ layer of silicon reduced $\mathrm{W}$ wrapped around all sides of a section of structural polysilicon. The silicon has been recessed using a $\mathrm{HF} / \mathrm{HNO}_{3}$ mixture in order to delineate the $\mathrm{W}$. Note the defect free coated surface after the aggressive etch.

Table I. Variation of tungsten film
thickness over different deposition times.
\begin{tabular}{|c|c|c|}
\hline $\begin{array}{c}\text { W } \\
\text { Deposition } \\
\text { time } \\
\text { (minutes) }\end{array}$ & $\begin{array}{c}\mathrm{W} \\
\left.\text { (atoms } / \mathrm{cm}^{2}\right)\end{array}$ & $\begin{array}{c}\text { W film } \\
\text { thickness } \\
(\AA)\end{array}$ \\
\hline 16 & $5.88 \mathrm{E} 16$ & 93 \\
\hline 8 & $4.83 \mathrm{E} 16$ & 76 \\
\hline 4 & $4.48 \mathrm{E} 16$ & 71 \\
\hline 4 & $4.55 \mathrm{E} 16$ & 72 \\
\hline 2 & $4.3 \mathrm{E} 16$ & 68 \\
\hline
\end{tabular}

enhanced during the wet etch process.

During the displacement reduction reaction of $\mathrm{Si}$ by $\mathrm{WF}_{6}$ shown earlier, the volume of Si consumed is greater than the volume of tungsten deposited. This allows $\mathrm{W}$ coatings to deposit in the very narrow gaps typically seen in MEMS devices. For every mole of tungsten formed, $3 / 2$ moles of polysilicon is consumed. Using the material parameters for Si and $\mathrm{W}$ and assuming the area of Si film to be the same as the W film; the ratio of the film thickness gives $t_{S i}=1.9 t_{W}$. This inherent reduction in volume results in $\mathrm{W}$ depositing in very narrow spaces. This is highly desirable for MEMS devices. Figure 3 shows the TEM micrograph of the $\mathrm{W}$ deposited on polysilicon using the selective self limiting deposition process.

\section{LIFETIME TESTS (WEAR RESISTANCE) OF TUNGSTEN-COATED MICROENGINES}

The microengine on the diagnostic module of a Sandia processed MEMS wafer was chosen for reliability and wear resistance assessment. It is of the same design as most of those tested in previous reliability experiments [18-20].

To make a clean comparison to a standard uncoated polysilicon microengine, we decided to use the same drive parameters and frequency $(1720 \mathrm{~Hz})$ used in an earlier test. All of the earlier tests were stressed with a large longitudinal force to accelerate the time to failure. The same was done with the tungsten-coated devices.

In our earlier tests without the coating, we observed a median time to failure of $4 \times 10^{5}$ accumulated cycles using a sample size of more than 20 microengines. This was performed in a controlled humidity environment of $39 \% \mathrm{RH}$. Using the same drive-signal parameters, but in ambient laboratory conditions $(30-50 \% \mathrm{RH})$, we observed a dramatic increase in the time to 


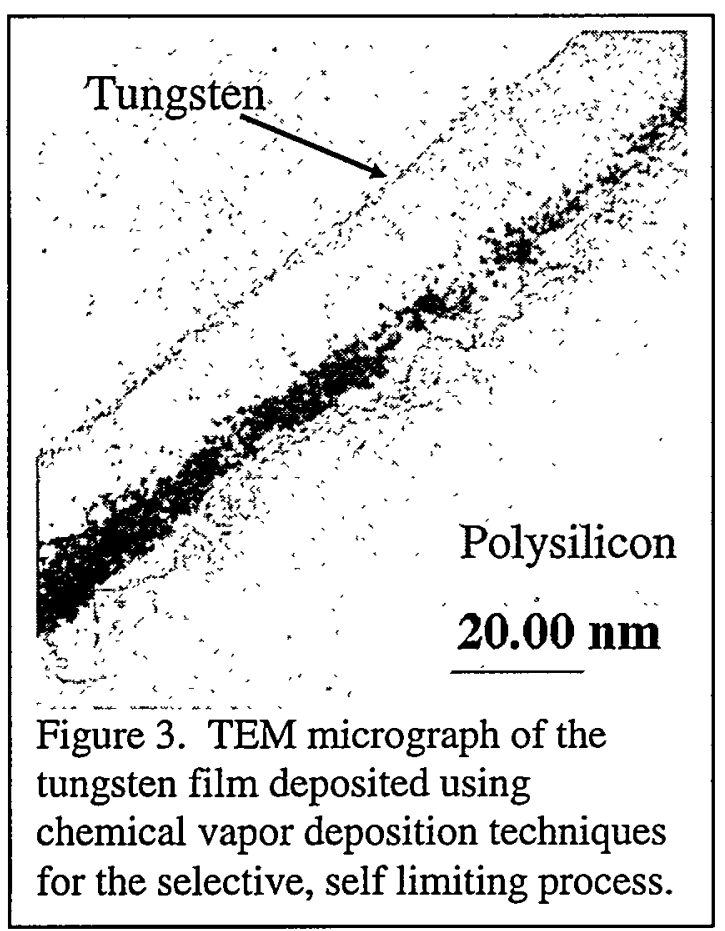

\section{ACKNOWLEDGEMENTS}

The United States Department of Energy under contract DE-AC04-94AL85000 supported this work. Sandia is a multiprogram laboratory operated by Sandia Corporation, a Lockheed Martin Company, for the United States Department of Energy. The authors acknowledge the staff in MDL for their efforts, Pat Shea for all the SEM work and Alex Pimental for all the focussed ion beam work.

\section{REFERENCES}

1. R. T. Howe, R. S. Muller, "Polycrystalline Silicon Micromechanical Beams", J. Electrochem Soc: Solid State Science \& Technology, vol. 103, No. 6, pp. 1420-1423, 1983.

2. E. J. Garcia and J. J. Sniegowski, "Surface Micromachined Microengine", Sensors and Actuators A, vol. 48, p. 203-214, 1995.

3. K. Deng, R. J. Collins, M. Mehrengany, and C. N. Sukenik, "performance impact of monolayer coating of polysilicon micromotors", J. Electro Chem Soc, vol 142, no 4, p. 12781285, 1995.

4. R. L. Alley, G. J. Cuan, R. T. Howe and K. Komvopoulos, "The effect of release-etch processing on surface microstructure stiction", Proceedings IEEE Solid State Sensor and Actuator Workshop, Hilton Head Is, SC, pp. 202-207, 1992.

5. R. Legtenberg, H. A. C. Tilmans, J. Elders, M. Elwenspoek, "Stiction of surface micromachined structures after rinsing and drying:model and investigation of adhesion mechanism", Sensors and Actuators A, vol. 43, pp. 230-238, 1994.

6. R. Maboudian, "Adhesion and friction issues associated with reliable operation of MEMS", MRS Bulletin, June, pp. 47-51, 1998.

7. R. Maboudian, "Surface processes in MEMS technology", Surface Science Reports, 30, p. 207-269, 1998. 
8. G. T. Mulhern, D. S. Soane and R. T. Howe, "Supercritical carbon dioxide drying of microstructures", Proceedings International Conference on Solid-State Sensors and Actuators (Transducers '93), Yokohama, Japan, pp. 296-299, 1993.

9. S. A. Henck, "Lubrication of digital micromirror devices ${ }^{\text {TM", }}$, Tribology Letters 3, p. 239-247, 1997.

10. P. F. Man, B. P. Gogoi, and C. H. Mastraugelo, "Elimination of post release adhesion in microstructures using thin conformal fluorocarbon films", Proceedings, Micro Electro Mechanical Systems '96, San Diego, CA USA p. 55-60.

11. D. R. Bradbury, J. E. Turner, K. Nauka and K. Y. Chiu, "Selective CVD tungsten as an alternative to blanket tungsten for submicron plug applications on VLSI circuits", IEDM, p. 273276, 1991.

12. M. Sekine, Y. Kakuhara, K. Yamazaki and Y. Murao, "Si reduction reaction mechanism of selective W-CVD", MRS, Advanced Metallization ULSI Applications, p. 255, 1991.

13. M. L. Yu, B. N. Eldridge, and R. V. Joshi, "Tungsten and other Refractory Metals for VLSI Applications III", edited by V. A. Wells (Mat. Res. Soc. Proc., Pittsburgh, PA, 1988).

14. M. L. Yu, B. N. Eldridge, and R. V. Joshi, "Deposition and Growth: Limits for

Microelectronics", edited by G. W. Rubloff (AIP Conf. Proc. 167, New York 1988), p. 202.

15. E. K. Broadbent and C. L. Ramiller, J Elctrochem. Soc.: Solid-State Science and

Technology, 1984, vol. 131, no 6, p. 1427.

16. M. L Green and R. A. Levy, J Elctrochem. Soc.: Solid-State Science and Techonolgy, 1985, vol. 132, no 5, p. 1243.

17. A. Kepten, A. Reisman, M. Ray, P. L. Smith, D. Temple, and F. Tapp, J. Electrochem. Soc, vol. 139, no 8, Aug 1992, p. 2331.

18. S. L. Miller, J. J. Sniegowski, G. LaVigne, and P. J. McWhorter, "Friction in Surface

Micromachined Microengines", Proceedings of SPIE Smart Electronics and MEMS Vol. 2722, San Diego, Feb. 28-29, 1996, pp. 197-204.

19. Danelle M. Tanner, W. M. Miller, W. P. Eaton, L. W. Irwin, K. A. Peterson, M. T. Dugger, D. C. Senft, N. F. Smith, P. Tangyunyong, and S. L. Miller, "The Effect of Frequency on the Lifetime of a Surface Micromachined Microengine Driving a Load," 1998 IEEE International Reliability Physics Proceedings, Reno, NV, 1998, pp. 26-35.

20. Norman F. Smith, William P. Eaton, Danelle M. Tanner, and James J. Allen, "Development of characterization tools for reliability testing of MicroElectroMechanical system actuators", SPIE's Vol. 3880, 1999, pp. 156-164. 